\section{HOSPITALIZACIONES Y MUERTES POR ABORTO CLANDESTINO EN PERÚ: ¿QUÉ DICEN LOS NÚMEROS?}

\section{HOSPITAL ADMISSIONS AND DEATHS DUE TO CLANDESTINE ABORTION IN PERU: WHAT DO THE NUMBERS REVEAL?}

\author{
Alvaro Taype-Rondan ${ }^{1, a}$, Nicolaz Merino-Garcia ${ }^{2, b}$
}

Sr. Editor. El aborto inseguro es definido como el procedimiento para terminar la gestación realizado por personas que no poseen las competencias necesarias $o$ en un ambiente sin los mínimos estándares médicos (1). $\mathrm{El}$ aborto inseguro es considerado una pandemia prevenible que afecta en mayor medida a países que presentan restricciones legales al respecto (2). En Perú, un país en el que se penaliza el aborto, muchas mujeres se someten de manera clandestina a una serie de procedimientos que acarrean un gran número de complicaciones y muertes maternas, cuyas cifras analizaremos a continuación.

¿Cuántos abortos inducidos se realizan en Perú? Se ha estimado una incidencia anual de 371420 abortos inducidos para el $2004{ }^{(3)}$. Estas cifras, probablemente, estén en aumento, debido al crecimiento demográfico y la restricción de métodos anticonceptivos a adolescentes.

¿Cuántos de estos abortos terminan en hospitalización? El número de hospitalizaciones anuales por abortos inducidos en el Perú se ha estimado en 54200 para $1989^{(4)}$ y 28652 para el $2013^{(5)}$. Esta aparente disminución puede deberse al incremento del uso clandestino de misoprostol, que resulta más fácil de utilizar y tiene un menor riesgo de complicaciones en comparación con otros procedimientos ${ }^{(2)}$.

¿Cuántas mujeres mueren a causa del aborto inducido? Para el año 2015, la Dirección General de Epidemiología del Perú reportó 414 muertes maternas, pero no detalla cuántas de estas han sido causadas por abortos clandestinos. Sin embargo, la Organización Mundial de

\footnotetext{
CRONICAS Centro de Excelencia en Enfermedades Crónicas, Universidad Peruana Cayetano Heredia. Lima, Perú.

Facultad de Medicina Humana, Universidad de San Martín de Porres. Lima, Perú.

a Médico cirujano; ${ }^{\text {b }}$ estudiante de Medicina.

Recibido: 08/07/2016 Aprobado: 07/09/2016
}

Citar como: Taype-Rondan Á, Merino-Garcia N. Hospitalizaciones y muertes por aborto clandestino en Perú: ¿Qué dicen los números? [carta]. Rev Peru Med Exp Salud Publica. 2016;33(4):829-30. doi: 10.17843/ rpmesp.2016.334.2573 la Salud (OMS) estima que para Sudamérica el $13 \%$ de las muertes maternas en el 2008 fueron causadas por aborto clandestino ${ }^{(6)}$, y un análisis realizado por Gerdts et al. estima que para países en los que predomina el aborto inseguro el $16 \%$ de las muertes maternas fueron causadas por aborto clandestino entre el 2000 y 2011 (7). En resumen, estas estimaciones indican que el $13 \%$ o el $16 \%$ de las muertes maternas $(53,8$ o 66,2 de las 414 muertes maternas reportadas para el 2015) serían causadas por el aborto inseguro. Otra aproximación puede realizarse utilizando el estimado de la OMS para Sudamérica de 10 muertes por aborto inseguro por cada 100000 nacidos vivos ${ }^{(6)}$, lo cual resulta en 57,8 muertes en Perú correspondientes a los 578130 nacidos vivos en el 2015 (Fuente: INEI. Estado de la población peruana. 2015). La semejanza entre las cifras obtenidas con estas tres estimaciones $(53,8 / 66,2 / 57,8$ muertes por año) nos sugiere una consistencia confiable, aunque cabe resaltar que estas estimaciones no abordan el caso específico de Perú.

En este contexto, la despenalización del aborto puede transformar el aborto clandestino inseguro en aborto seguro, disminuyendo exponencialmente las hospitalizaciones y la mortalidad asociadas. ¿Cuántas hospitalizaciones se evitarían? Recordemos que se han estimado 28652 hospitalizaciones anuales por aborto inducido. El aborto seguro presenta menos de 0,4\% de hospitalizaciones, por lo que los 371420 abortos anuales presentarían apenas 1486 hospitalizaciones. De esta manera, al despenalizar el aborto se evitarían $28652-1486=27166$ hospitalizaciones anualmente.

¿Cuántas muertes se evitarían? Como hemos mencionado, se estima que cada año mueren 58 mujeres por aborto inducido en Perú. El aborto realizado en condiciones seguras tiene una mortalidad menor a 1/100 000 abortos, por lo cual los 371420 abortos anuales en Perú presentarían como máximo 4 muertes. De esta manera, al despenalizar el aborto se evitarían 54 muertes al año.

En conclusión, a pesar de que en Perú no se cuentan con cifras sobre el impacto del aborto inseguro, se estima que cada año causa 28652 hospitalizaciones y 58 muertes. Además, la no despenalización del aborto traería como consecuencia 27166 hospitalizaciones y 54 muertes al año en el Perú, cifras que merecen ser tomadas en consideración al debatir este tema.

Contribuciones de autoría: ATR y NMG han participado en la concepción y redacción del artículo

Conflictos de interés: los autores declaran no tener conflictos de interés con respecto a la publicación del presente artículo.

Financiamiento: autofinanciado. 


\section{REFERENCIAS BIBLIOGRÁFICAS}

1. Ganatra B, Tuncalp O, Johnston HB, Johnson Jr BR, Gulmezoglu AM, Temmerman M. From concept to measurement: operationalizing WHO's definition of unsafe abortion. Bulletin of the World Health Organization. 2014;92(3):155-.

2. World Health Organization. Safe Abortion: Technical and Policy Guidance for Health Systems, Geneva: WHO, 2012. On-line at: http://appswhoint/iris/ bitstream/10665/70914/1/9789241548434_engpdf. 2012.

3. Delicia F. El aborto clandestino en el Perú. Editorial Flora Tristán Lima. 2006.

4. Henshaw SK, Singh S, Haas T. The incidence of abortion worldwide. International family planning perspectives. 1999:S30-S8.

5. Singh S, Maddow-Zimet I. Facility-based treatment for medical complications resulting from unsafe pregnancy termination in the developing world, 2012: a review of evidence from 26 countries. BJOG: An International Journal of Obstetrics \& Gynaecology. 2015.

6. Department of Reproductive Health and Research WHO. Unsafe abortion: global and regional estimates of the incidence of unsafe abortion and associated mortality in 2008. Sixth edition. 2011.

7. Gerdts C, Vohra D, Ahern J. Measuring unsafe abortionrelated mortality: a systematic review of the existing methods. PloS one. 2013;8(1):e53346.

Correspondencia: Alvaro Taype-Rondan

Dirección: Avenida Armendáriz 497, Miraflores, Lima 18, Perú

Correo electrónico: alvaro.taype.r@upch.pe

Teléfono: (+51) 2416978

\section{ALTA FRECUENCIA DE JUGUETES CONTAMINADOS CON Staphylococcus aureus EN HOSPITALIZACIÓN PEDIÁTRICA}

\author{
HIGH NUMBER OF TOYS CONTAMINATED \\ WITH Staphylococcus aureus IN A PEDIATRIC \\ HOSPITALIZATION SERVICE
}

\begin{abstract}
Rosmery Ruiz',a, Johanna Quijandria ${ }^{1, a}$, Jose Luis Rojas-Vilca ${ }^{1, b}$, Steev Loyola ${ }^{1, c}$
\end{abstract}

Sr. Editor. Los juguetes expuestos a ambientes hospitalarios pueden ser reservorios de diversos patógenos comúnmente implicados en infecciones intrahospitalarias $(\mathrm{IIH})^{(1-4)}$. Las bacterias del género Staphylococcus resistentes a antimicrobianos (RAM) son de particular importancia en ambientes de cuidados críticos, debido a su capacidad de causar infecciones a la sangre, así como otras IIH de difícil tratamiento ${ }^{(4)}$. El objetivo del presente estudio piloto fue determinar la frecuencia de contaminación con Staphylococcus aureus en juguetes de niños hospitalizados.

Durante noviembre de 2015 se realizó un estudio descriptivo transversal en seis áreas de hospitalización de un centro especializado en atención pediátrica de Lima, Perú: Unidad de Quemados, Traumatología, Cirugía General, Neumología, Infectología y Unidad de Cuidado Intensivos (UCI). Se incluyeron todos los juguetes de los niños hospitalizados. En caso de niños con múltiples juguetes, se eligió un juguete de forma aleatoria. El proyecto de investigación tuvo aprobación del Comité de Ética de la Universidad Peruana Cayetano Heredia (SIDISI: 64894) y del Centro de Atención Pediátrico.

Las muestras fueron colectadas usando técnicas estériles. Un hisopo de algodón fue embebido en caldo tripticasa de soya (CTS) y rotado por toda la superficie del juguete. Luego, el hisopo fue sumergido en un tubo con CTS e incubado en condiciones aeróbicas a $37{ }^{\circ} \mathrm{C}$ por $24 \mathrm{~h}$. El aislamiento y caracterización de Staphylococcus aureus (SAU) fue realizado por procedimientos estándares de microbiología. La susceptibilidad antibiótica de los SAU fue determinada por el método de disco difusión, e incluyó discos de oxacilina (1 ug), cefoxitina (30 ug), rifampicina (5 ug), gentamicina (10 $\mathrm{ug})$, teicoplanina (30 ug), sulfametoxazol-trimpetropin

\footnotetext{
Universidad Peruana Cayetano Heredia. Lima, Perú.

astudiante de Tecnología Médica; ${ }^{\mathrm{b}}$ médico; ${ }^{\mathrm{c}}$ tecnólogo médico Recibido: 11/08/2016 Aprobado: 24/08/2016
}

Citar como: Ruiz R, Quijandria J, Rojas-Vilca JL, Loyola S. Alta frecuencia de juguetes contaminados con Staphylococcus aureus en hospitalización pediátrica. [carta]. Rev Peru Med Exp Salud Publica. 2016;33(4):830-2. doi: 10.17843/rpmesp.2016.334.2574 